\title{
Design and Test of Combined Air Suction Cotton Breed Seeder
}

\author{
Yudao Li, ${ }^{1,2,3}$ Zhanhua Song, ${ }^{1,2}$ Fade Li, ${ }^{1,2}$ Yinfa Yan, ${ }^{1,2}$ Fuyang Tian $\mathbb{D}^{1,2}$ \\ and Xuezhen Sun $\mathbb{1 D}^{3}$ \\ ${ }^{1}$ College of Mechanical and Electronic Engineering, Shandong Agricultural University, Tai'an 271018, China \\ ${ }^{2}$ Shandong Key Laboratory of Horticulture Machinery and Equipment, Tai'an 271018, China \\ ${ }^{3}$ College of Agriculture, Shandong Agricultural University, Tai'an 271018, China
}

Correspondence should be addressed to Xuezhen Sun; sunxz@sdau.edu.cn

Received 17 May 2020; Accepted 29 June 2020; Published 23 July 2020

Academic Editor: Hidetaka Noritomi

Copyright (c) 2020 Yudao Li et al. This is an open access article distributed under the Creative Commons Attribution License, which permits unrestricted use, distribution, and reproduction in any medium, provided the original work is properly cited.

In view of such a phenomenon that nowadays cotton breeding and seeding mainly depend on artificial planting in China, a kind of combined air suction cotton breed seeder was designed, which is mainly composed of combined air suction seed metering device, three-way switch device, waste seed recovery device, vacuum fan, and so on. It can sow two rows at a time, and the line spacing, plant spacing, and sowing depth can be continuously adjusted to achieve precise sowing. The model of "suck before and blow after" is adopted in seed clearing, which makes seed clearing both clean and rapid. The force, speed, and acceleration of cotton seed are theoretically analyzed when the seed metering device is filled with seeds and then determines the main structural parameters and motion parameters of the device. This paper takes Lumianyan No. 37 as the research object, adopts the single-factor test and the quadratic regression rotation orthogonal test, selects the forward speed, air pressure, and groove plate width of the air suction cup as the experimental factors, and conducts an experiment of the seeder's performance, by analyzing the influence law of the seeder's velocity on its seeding variation coefficient. This paper concludes that the coefficient of variation is small when the velocity is $1.2-1.5 \mathrm{~m} / \mathrm{s}$ and finds the optimal range of unit velocity when sowing and finally builds the mathematical models including multiples index and missing index. After parameter optimization, this paper makes the optimal parameters for sure; that is, the seeder's velocity ranges from 1.3 to $1.5 \mathrm{~m} / \mathrm{s}$, wind pressure ranges from 2.5 to $2.8 \mathrm{kPa}$, and the width of the air suction groove ranges from 2.6 to $2.8 \mathrm{~mm}$. At this time, the multiples index and missing index of the combined air suction cotton breed seeder are less than $3 \%$, whose sum total is less than $5 \%$. In the field test, the seed clearing performance of the seed clearing system is tested, and the seed clearing rate has reached $100 \%$, meeting the seeding requirements in cotton tablets.

\section{Introduction}

Cotton is an important economic crop in China [1]. Cotton breeding can provide important guarantees for cotton production [2]. At present, most of the cotton breeding in China adopts artificial planting [3], which features high labor intensity and low production efficiency, and will reduce the accuracy of breeding test. Nowadays, crop breeding machines in China are mainly used for wheat, corn, soybean, rape, and other crops. This paper adopts those machines used, manufactured by the Hongxinglong Research Institute of the Farm Reclamation Bureau in Heilongjiang Province, Agricultural Machinery Research Institute, the Jiangsu Lixiahe Agricultural Academy, and Suning in Hebei Province and other places
[3-7]. Tablet seeder used here is produced by foreign countries including Wintersteiger in Austria, Haldrup in Germany, Cone in France, and Almaco in the United States. In order to improve the dispersion uniformity of crop seeds by the tablet seeder in terms of its seeding device [8], domestic scholar Prof. Shang Shuqi and his team members study the seeding device of tablet seeders in cone-disc form and determine the optimal working parameters. Professor Liao Qingxi leads his team to design a belt-type precision seed metering device suitable for rape breeding [9-13]. Professor Chen Haitao's team has developed a precision seeding machine for tablet breeding that can quantitatively adjust the plant spacing and seed spacing [5]. According to the actual needs and agronomic requirements of cotton tablet breeding work in Xinjiang, Yang 
Binghui has designed a precision seeding machine for cotton tablet that can be used for spot seeding and seeding on mulch, easy seed clearing, missing seeding monitoring and warning, marking and the reminder of missing seeding, and other functions [14].

Based on the principles of tablet seeders and with the reference of Wintersteiger's classification of seed metering devices, this paper makes improvement mainly from the following five aspects. There are three differences among the seed metering devices (the width of the air suction groove is different; there is a seed clearing funnel, and the model of "suck before and blow after" is adopted in seed clearing). There are two differences between the overall seeders (suspension type and continuously adjustable plant spacing). Combined with the agronomic characteristics of tablet's cotton breeding, this paper has designed the air suction cotton breed seeder featuring precise seeding, clean cleaning, and rapid and easy operation and further designed its overall structure and key components. At the same time, field trials are carried out to test the seeding performance.

\section{Agronomic Requirements of Cotton Tablet Seeding}

Cotton is a dicotyledonous plant $[15,16]$. Deep cultivation makes it difficult to unearth, and the seedlings will be weak. What is worse, it is even unable to unearth. By contrast, shallow cultivation makes the cotyledon unearth together with shell [17], which influences the growth of cotton seedlings. Therefore, the sowing depth of cotton should be appropriately suitable $[18,19]$. Generally speaking, the sowing depth should range from 1 to $5 \mathrm{~cm}$ and be continuously adjustable. Cotton planting should be done with one hole and one grain [20] to avoid reseeding and missing seeding. In general, the plant spacing of the cotton tablet planting in the Yellow River Basin can be continuously adjustable from 15 to $25 \mathrm{~cm}$. The line spacing is continuously adjustable from 60 to $90 \mathrm{~cm}$. To realize continuous change of sowing depth, plant spacing provides conditions for the breeding tablet tests at different levels, as well as basic conditions for test standardization and reliability.

Diagram of cotton tablet planting is shown in Figure 1. In terms of the first tablet, its plant spacing should be set before being seeded, and the line spacing as well as sowing depth should be adjusted. Then, the cotton seed can be sown in the first tablet, and the seeder begins to work. As for the remaining cotton seeds after being planted in the first tablet, they should be cleaned to avoid mixture with the cotton seed in the second tablet to be planted [21]. After cleaning the cotton seed of the first tablet in a thorough and rapid manner [22], we start to add the cotton seed planted in the second tablet. If the plant spacing, line spacing, and sowing depth of the second tablet change, it should be adjusted in line with the requirements of this tablet. If the plant spacing, line spacing, and sowing depth of the second tablet remain unchanged, we will plant the seeds in accordance with the unified procedure. The length of the tablet is from 2 to $10 \mathrm{~m}$. It can be concluded that there are about 70-400 cotton tablets that can be sown on an acre of land $\left(666.7 \mathrm{~m}^{2}\right)$. There

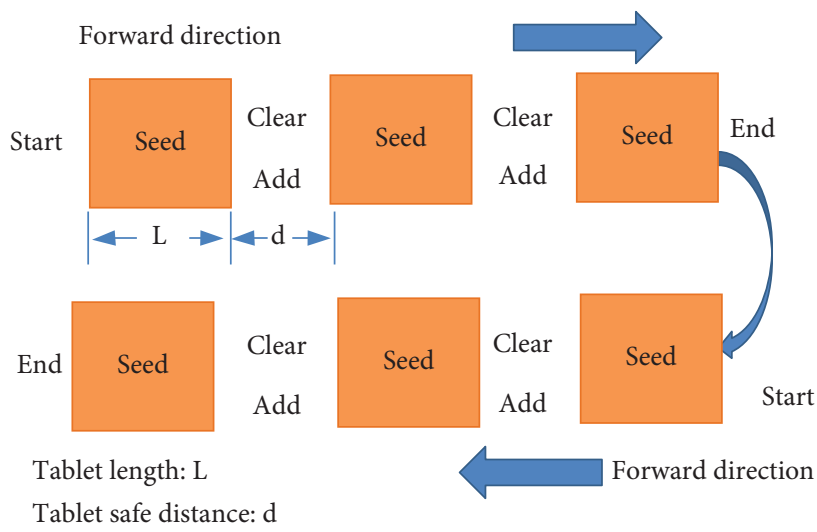

Figure 1: Diagram of tablet planting.

is a safe distance in each tablet planting, and the safe distance is generally from 0.5 to $1 \mathrm{~m}$. On the one hand, the seedlings come out unevenly after sowing; by so doing, tablet overlapping can be avoided. On the other hand, the safe distance makes it convenient to walk during the later experimental investigation [23]. This puts high demands on the accuracy and speed of the cotton breed seeder. Diagram of tablet planting is shown in Figure 1.

\section{Overall Structure and Working Principle of the Combined Air-Suction Cotton Breed Seeder}

The combined air suction cotton breed seeder is mainly composed of seeding system, seed clearing system, and control system. The overall structure is shown in Figure 2. The seeding system mainly consists of vacuum fan, vacuum pipeline, air pump, three-way switching device, and combined air suction seeding device. The seed clearing system is mainly made up of vacuum fan, vacuum pipeline, air pump, three-way switching device, and waste seed recovery room. The control system mainly consists of encoder, single chip microcomputer, electromagnetic valve, and so on.

The combined air suction cotton breeding seeder is connected to the seeder through the tractor's three-point suspension device during operation, while the tractor power output shaft is connected to the seeder power input shaft through a universal joint coupling [24]. It can provide power for vacuum fans and air pumps. When seeding, the vacuum fan provides the seed meter with vacuum negative pressure to ensure that the seeding device can suck the seed. During the seed clearing, the vacuum fan also provides vacuum negative pressure to the seed clearing pipeline to achieve "seed suction" so that the remaining seeds can be recycled to the waste seed recycling room thoroughly and rapidly. The air pump offers pressure to the cylinder, and the three-way switching device is controlled by the expansion and contraction of the cylinder to change the direction of the air flow, so that the vacuum negative pressure provided by the vacuum fan can be switched between seeding and clearing states. During seed clearing, the air pump provides positive pressure to storage seed shell, which can realize "seed 


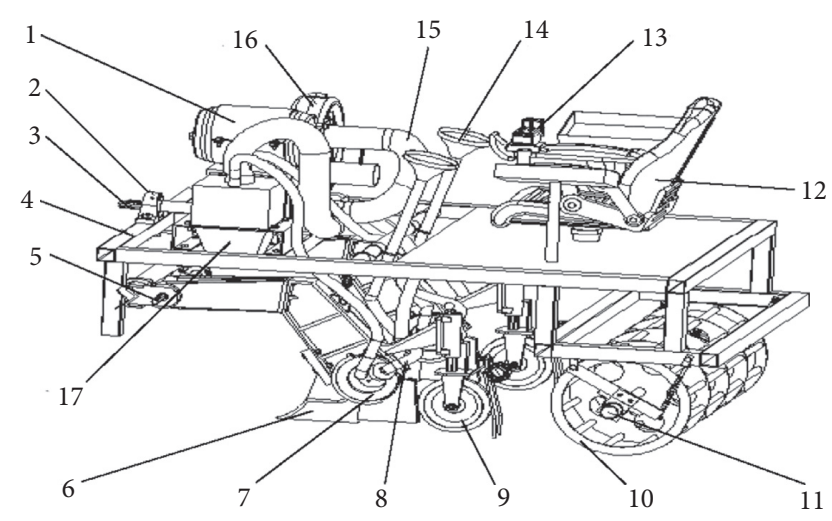

Figure 2: 3D drawing of seeder. (1) Air pump. (2) Bearing. (3) Power input shaft. (4) Frame. (5) Spline shaft. (6) Opener. (7) Seed metering device. (8) Guided seed tube. (9) Press wheel. (10) Land wheel. (11) Encoder. (12) Work platform. (13) Electromagnetic valve. (14) Aid seed funnel. (15) Vacuum tube. (16) Vacuum fan. (17) Waste seed recovery room.

blowing." Seed clearing realizes the model of "suck before and blow after."

The seeder's ground wheel will rotate when it works. The encoder is used for collecting rotation speed of the encoder and further controlling the motor to drive the seed metering device. The motor ensures the accuracy of the plant spacing, so that the plant spacing can be continuously adjusted. The adjustment of plant spacing is mainly realized by adjusting the distance between two row furrows. The sowing depth can be adjusted by the bolts of the press wheel, so that the sowing depth can be adjusted in a continuous way.

\section{Structural Design and Analysis of the Seed Meter of the Combined Air-Suction Cotton Breed Seeder}

4.1. Structural Design of the Seed Meter of the Combined AirSuction Cotton Breed Seeder. The seed metering device is composed of a seed metering shell, a disk drive, a guide groove plate, an air suction cup, a forced seeding plate, a storage seed shell, etc. The shell of seed meter is fixed on the furrow, and the motor rotates with the disk drive with the guide groove, the air suction plate, and the forced seeding plate rotating simultaneously. As can be seen in Figure 3(b), the cotton seeds needed for planting in the tablet are dropped at the aid seed funnel.

The cotton seed falls into the storage seed shell with the operation of seed guided tube. The vacuum fan provides vacuum negative pressure which is transmitted to the air suction plate through the guide groove plate.

The combination of the guide groove plate and the air suction plate will form an approximately rectangular air suction hole, as shown in Figure 4. The cotton seed will move to the periphery of the circumference along the track of the guide groove plate as the air suction plate (the air suction plate is in the front of the physical picture in Figure 5) rotates.
When the cotton seed moves to the periphery of the air suction plate, it will enter the confined space composed of 1 to 6 faces as shown in Figure 5. The confined space is composed of 3 faces of the seed storage shell, 2 sides of the guide groove plate, and 1 face of the air suction plate, summing to 6 faces. The cotton seed rotates while guide groove plate is rotating. The seeding shell has an opening at the lower end. Therefore, when the cotton seed moves down, it will fall into seed ditch of the furrow due to gravity.

After a cotton tablet was sown, the three-way switching valve will start to rotate through the control system to switch the vacuum negative pressure to the waste seed recovery room. The vacuum negative pressure is transferred to the suction port of the seed storage shell to suck the seeds back to the waste seed recovery chamber. The model of "suck before and blow after" is adopted in seed clearing. Therefore, the cotton seed of the previous tablet will not be stored in the seed metering device. When planting the next tablet, the cotton seed can be added to the storage seed shell through the seed port.

\subsection{Analysis of the Force, Speed, and Acceleration of Cotton Seed When the Seed Metering Device of the Combined Air- Suction Cotton Breed Seeder Is Filled with Seeds}

4.2.1. Stress Analysis of Cotton Seeds during Seed Filling. Seed-filling performance is a key part of the seeding process and will directly affect the multiples index and missing index. According to the adsorption posture of cotton seeds and in combination with the theoretical analysis of the vertical disc air suction seed metering device, the force diagram of a single-grain cotton seed in the seed-filling stage is obtained, as shown in Figure 6. The guide groove and the air suction disk groove form an air suction hole, moving constantly. To easily conduct force analysis of cotton seeds $[23,24]$, the following assumptions are made:

(1) It is assumed that the distance between the seed suction holes is greater than its length and width, and the area of the seed suction holes is smaller than the projected area of the seeds in any direction, so as to ensure that each seed suction hole can only absorb one seed and study the force condition of each seed in the seed suction hole.

(2) The soil of the seeder is flat and not undulating when working in the field; the vibration of the seeder is ignored.

(3) It is assumed that the airflow field of the confined vacuum chamber in the seed metering device is even in the course of work, and the parameters are set as steady flow. Cotton seeds can be adsorbed on the air suction hole and steadily move outward with the rotation of the air suction hole, instead of sliding. For any position on the guide groove, rolling should meet the following conditions of balanced force: 


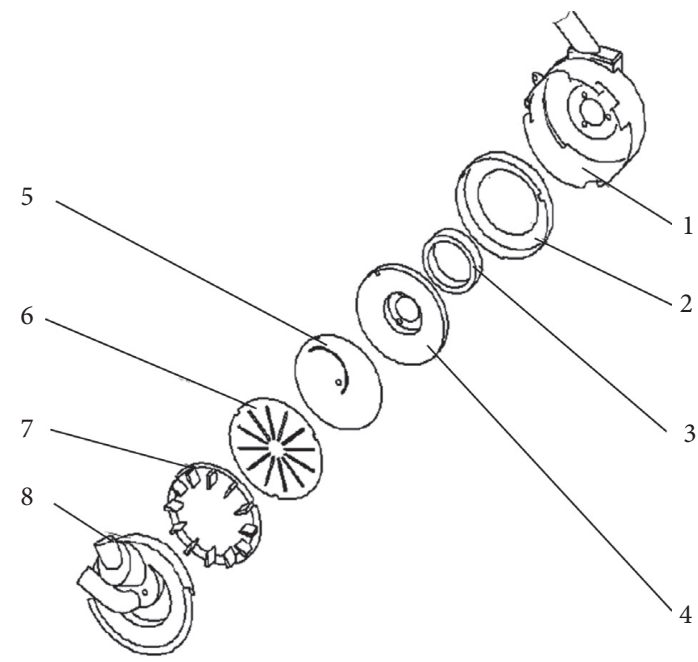

(a)

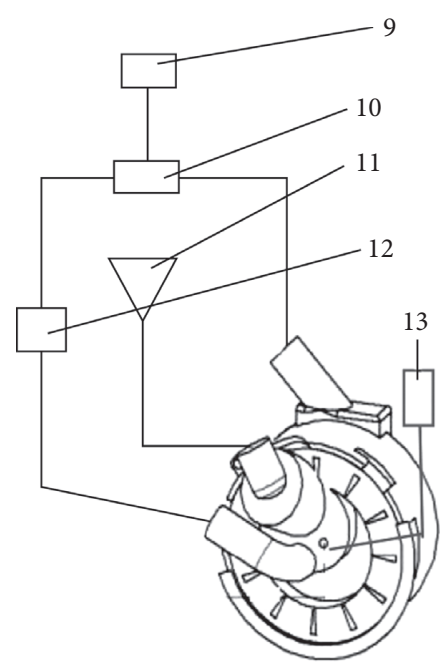

(b)

FIGURE 3: Structure of air suction seed metering device. (a) Seed meter exploded view. (b) Seed meter combination view. (1) Shell of seed meter. (2) Disk drive. (3) Bearing. (4) Guide groove plate fixing device. (5) Guide groove plate. (6) Air suction plate. (7) Forced seeding plate. (8) Storage seed shell. (9) Vacuum fan. (10) Three-way switching device. (11) Aid seed funnel. (12) Waste seed recovery device. (13) Air pump.

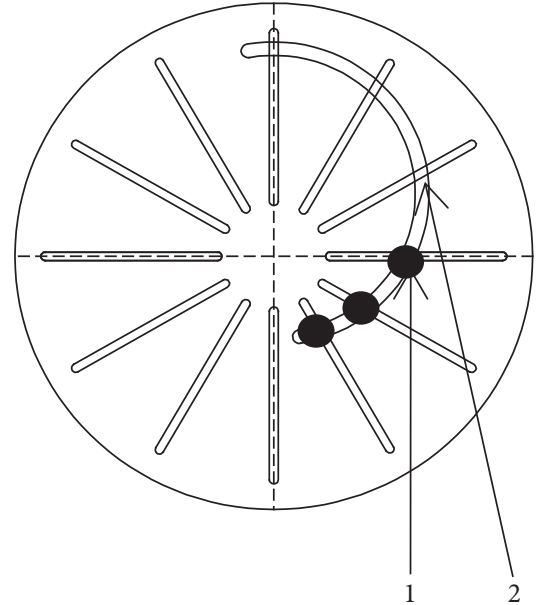

(a)

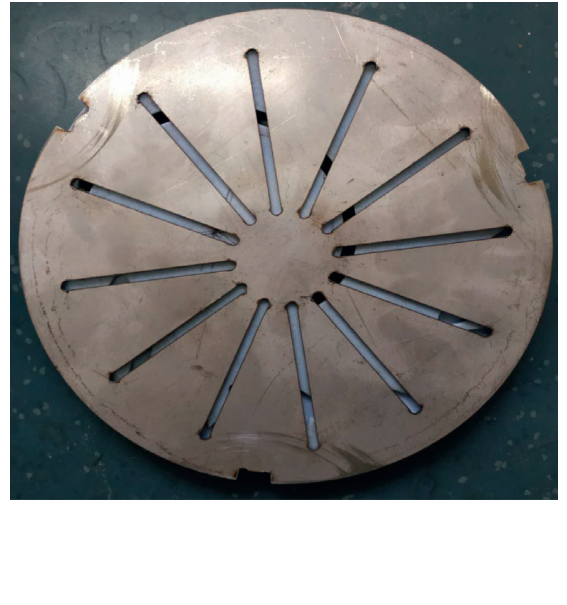

(b)

Figure 4: Combination of guide groove plate and air suction plate. (a) Design diagram. (b) Physical diagram. (1) Cotton seed. (2) Hole of combined air suction.

$$
\begin{aligned}
m a_{a}^{n} & =\left(F_{f 1}-G\right) \cos (\theta-\phi)+F_{f 2} \cos \phi+F_{N 2} \sin \phi, \\
m a_{a}^{t} & =\left(F_{f 1}-G\right) \sin (\theta-\phi)+F_{f 2} \sin \phi+F_{N 2} \cos \phi, \\
F_{f 2} & =\mu F_{N 2}, \\
F_{f 1} & =\mu F_{N 1}, \\
F_{N 1} & =F_{N 2}=P, \\
P & =p a b .
\end{aligned}
$$

In the formula, $p$ is vacuum negative pressure, $\mathrm{Pa}$; $a$ is width of air suction plate, $\mathrm{mm}$; $b$ is width of guide groove, $\mathrm{mm} ; F_{N 1}$ is support force exerted by the guide groove in the vertical plane, $N ; F_{N 2}$ is support force exerted by the air suction plate in the vertical plane, $N ; F_{f 2}$ is friction force exerted by the air suction plate when the seed moves outward, $N ; F_{f 1}$ is friction force exerted by the guide groove when the seed moves outward, $N ; G$ is gravity, $N ; \varphi$ is the angle between $v_{\mathrm{a}}$ and $v_{\mathrm{e}} ; \theta$ is the angle between the radius $r$ of the air suction plate and the vertical direction.

There are eight unknown quantities including $F_{N 1}, F_{N 2}$, $F_{f 2}, F_{f 1}, P, a_{a}^{n}, a_{a}^{t}$, and $p$ in the formula, and the speed and acceleration of cotton seed on the air suction plate need to be analyzed.

4.2.2. Analysis of Cotton Seed Speed. According to the motion state of cotton seed on the air suction plate, it can be analyzed that the absolute motion of cotton seed is circular 


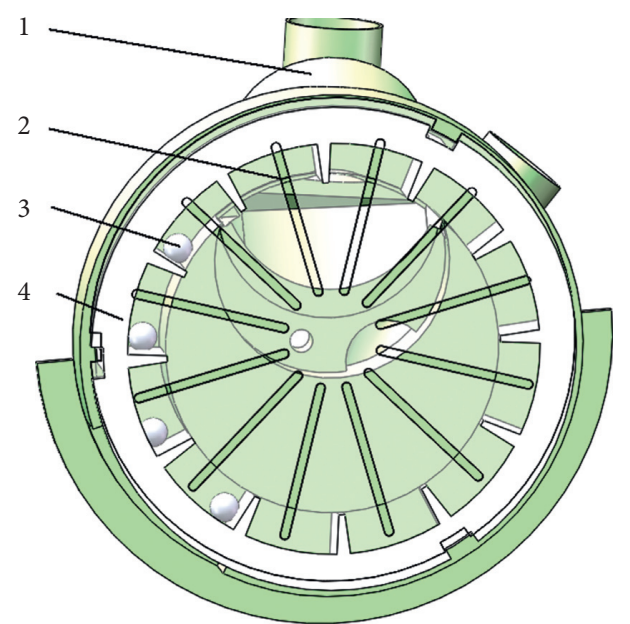

Figure 5: Cotton seeds in confined space. (1) Storage seed shell. (2) Air suction plate. (3) Cotton seed. (4) Guide groove plate.
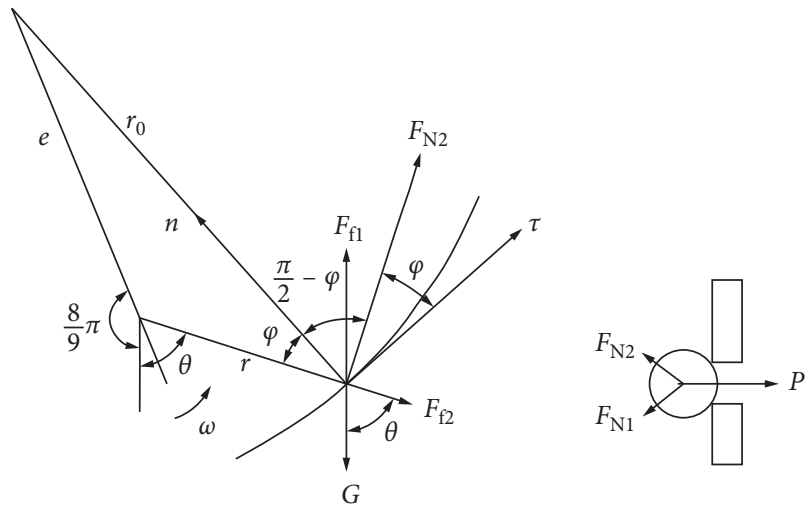

Figure 6: Force analysis of cotton seeds.

motion, which can be decomposed into linear motion opposite to air suction plate and fixed-axis rotation following the air suction plate. The velocity vector is shown in Figure 7. According to the composition of velocity law of the points, the absolute velocity of cotton seed satisfies the following relation:

$$
\begin{aligned}
\vec{v}_{a} & =\vec{v}_{e}+\vec{v}_{r}, \\
v_{e} & =\omega r \\
r & =\sqrt{r_{0}^{2}+e^{2}-2 r_{0} e \cos \theta}, \\
\theta & =\omega t \\
\phi & =\arccos \sqrt{\frac{r^{2}+r_{0}^{2}-2 r r_{0}}{2 r r_{0}}} .
\end{aligned}
$$

In the formula, $v_{e}$ is transport velocity, $\mathrm{m} / \mathrm{s} ; v_{r}$ is relative velocity, $\mathrm{m} / \mathrm{s} ; \omega$ is angular velocity of air suction plate, $\mathrm{rad} / \mathrm{s}$.

According to the triangle relationship,

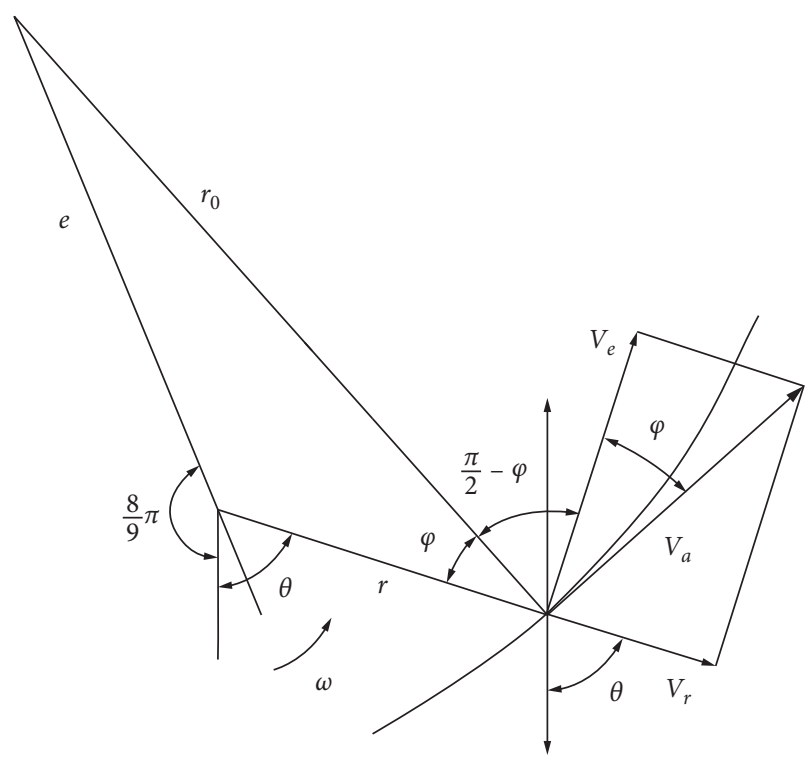

Figure 7: Analysis of cotton seed movement speed.

$$
\begin{aligned}
& v_{a}=\frac{\omega\left(r^{2}+e^{2}-2 r e \cos \theta\right)}{r-e \cos \theta}, \\
& v_{r}=\omega \sqrt{r^{2}+e^{2}-2 r e \cos \theta} \tan \phi .
\end{aligned}
$$

4.2.3. Analysis of Cotton Seed Acceleration. In order to analyze the acceleration changes in the process of seed movement, the acceleration analysis is shown in Figure 8. In this formula, $\overrightarrow{a_{a}^{t}}$ and $\overrightarrow{a_{e}^{t}}$ refer to the tangential acceleration of its absolute acceleration and transport acceleration respectively while $\overrightarrow{a_{a}^{n}}$ and $\overrightarrow{a_{e}^{n}}$ refer to the normal acceleration of its absolute acceleration and transport acceleration, respectively. Also, $\overrightarrow{a_{r}}$ means the relative acceleration while $\overrightarrow{a_{c}}$ means the Coriolis acceleration.

According to the composition theorem of particle acceleration, the acceleration of cotton species has the following relationship:

$$
\overrightarrow{a_{a}^{\tau}}+\overrightarrow{a_{a}^{n}}=\overrightarrow{a_{e}^{n}}+\overrightarrow{a_{e}^{\tau}}+\overrightarrow{a_{r}}+\overrightarrow{a_{c}} .
$$

Projected in the normal and tangential directions, respectively,

$$
\begin{aligned}
& a_{a}^{n}=a_{e}^{\tau} \sin \phi+a_{c} \sin \phi+a_{e}^{n} \cos \phi-a_{r} \cos \phi, \\
& a_{a}^{\tau}=a_{e}^{\tau} \cos \phi+a_{c} \cos \phi+a_{r} \sin \phi-a_{e}^{n} \sin \phi .
\end{aligned}
$$

In the formula, $a_{e}^{n}=\omega^{2} r, a_{e}^{\tau}=0, a_{c}=2 \omega v_{r}$, and $a_{r}=\left(\mathrm{d} v_{r} / \mathrm{d} t\right)$.

Sorting out the formula,

$$
\begin{aligned}
& a_{a}^{n}=r \tan \phi \sin \phi+\omega^{2} r \cos \phi+\frac{\omega \omega_{1}}{2 r} \cos \phi \sin \theta \\
& a_{a}^{\tau}=\omega^{2} r \sin \phi-\frac{\omega^{2}}{2 r} \sin \phi \sin \theta
\end{aligned}
$$

After $a_{a}^{n}$ and $a_{a}^{t}$ are obtained from formulas (6) and (7), the eight unknown quantities in formula (1) can be obtained. 


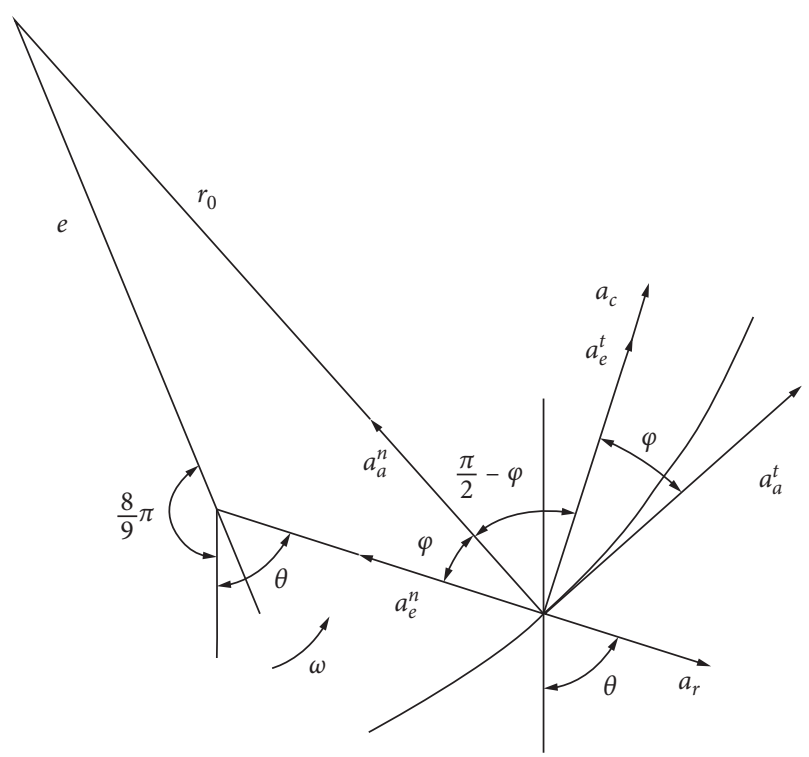

Figure 8: Analysis of cotton seed acceleration.

The friction coefficient $\mu$ of cotton seed and air suction plate is taken as $0.72 . r_{0}$ equals $40 \mathrm{~mm}$ and $e$ equals $20 \mathrm{~mm}$. The cotton seed used in the test is Lumianyan No. 37. The weight of one thousand cotton seeds is $95.35 \mathrm{~g}$. The seed's diameter is $5.3 \mathrm{~mm}$; the area of the air suction hole is designed to be $12 \mathrm{~mm}^{2}$; that is, the width of the air suction plate is $3 \mathrm{~mm}$, and the width of the guide groove equals $4 \mathrm{~mm}$. When the air suction plate rotates at the speed of $15 \mathrm{r} / \mathrm{min}$, the calculated critical value is $2180.89 \mathrm{~Pa}$.

\section{Switch Device Design of the Combined Air- Suction Cotton Breed Seeder}

The seed metering system and the seed clearing system share a set of vacuum negative pressures provided by a vacuum fan. This requires the seeder to have a device that switches between the two functions and a control device as well. The switch device is required to be fast and easily operated with good air tightness. This switch device is designed to meet all the above requirements. This switching device is mainly composed of electromagnetic valve, cylinder, three-way switch device, fixed frame, link, and so on. Physical map of the switch device is shown in Figure 9.

When doing seed metering, turn on the vacuum fan and open the air pump connected to the electromagnetic directional valve. After the electromagnetic directional valve is driven to work, the positive pressure air flow generated by the air pump enters the cylinder and pushes its telescopic pole to move, rotating flange and axis of rotation. As a result, the valve plate on the axis of rotation opens the seed metering passage in the three ways; that is, the vacuum fan is connected to the seed metering channel, so that vacuum negative pressure is generated at the end of its combined air suction hole which is used to adsorb the seeds for seed metering.

The seed clearing operates in a similar way with that of seed metering described above. The electromagnetic directional valve changes direction, and the movement of the

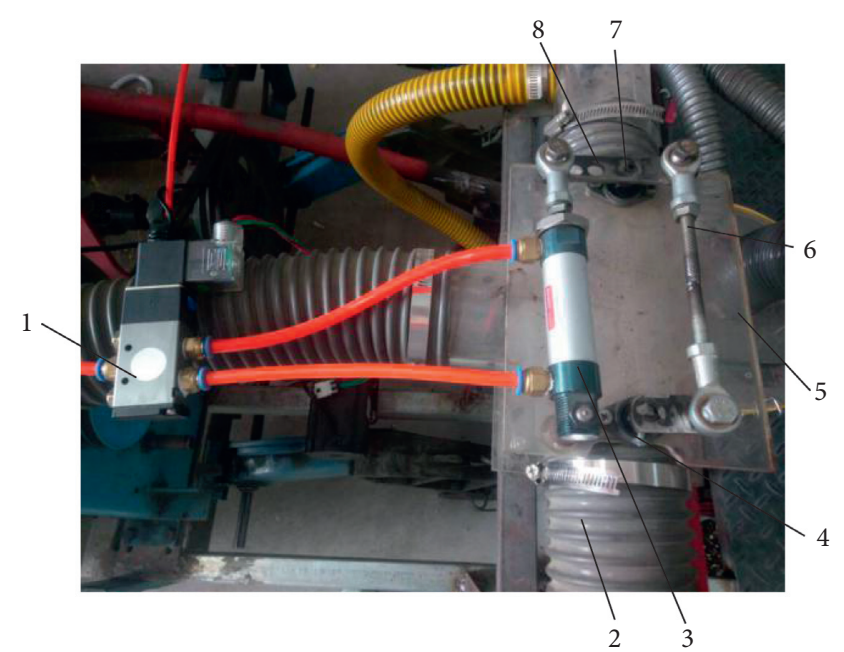

Figure 9: Physical map of the switch device. (1) Electromagnetic valve. (2) Three-way switch device. (3) Cylinder. (4) Bearing. (5) Fixed frame of three-way switch device. (6) Link. (7) Axis of rotation. (8) Flange.

cylinder telescopic pole drives the valve plate at the other end to rotate, closing the seed metering channel, and the vacuum negative pressure of the seed outlet at the end of the seeding channel disappeared. Seed metering stops then. At the same time, the seed clearing channel is opened; that is, the vacuum fan and the seed clearing channel are connected, and the vacuum negative pressure generated by the vacuum fan produces negative pressure at the end of the seed clearing channel to suck the waste seeds stored in the storage seed shell to the waste seed storage room. By so doing, waste seeds are collected.

\section{Seed Clearing System Design of the Combined Air-Suction Cotton Breed Seeder}

The seed clearing system of the combined air suction cotton breed seeder mainly includes the seed meter connection tube, the waste seed recovery room, the vacuum tube of the waste seed recovery room, the waste seed recovery room cover, the bolt, the three-way switch device, the vacuum fan, the air pump, and the storage seed shell. The schematic diagram of the seed clearing system is shown in Figure 10.

The vacuum tube on the cover of the waste seed recovery room is connected to the existing vacuum fan, and the seed meter connection tube on the cover of the waste seed recovery room is connected to the waste seed outlet end of the seeder's storage seed shell through a hose. During seed clearing, the three-way switch device controlled by the electromagnetic valve connects the vacuum fan to the vacuum tube of the waste seed recovery room. The vacuum negative pressure generated by the vacuum fan puts the entire waste seed recovery room in a vacuum state, and the vacuum negative pressure in the waste seed recovery room generates an adsorption effect on the waste seed in the storage seed shell through the hose. At the same time, the air pump is turned on, and the positive pressure generated by 


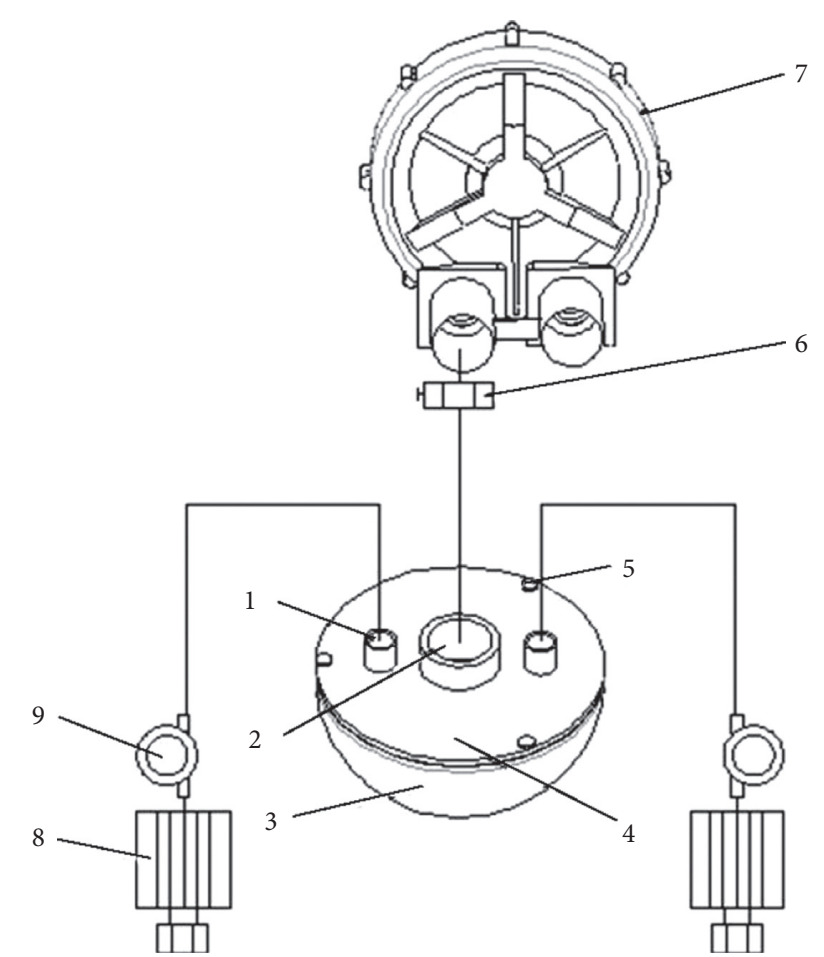

Figure 10: Schematic diagram of seed clearing system. 1. Seed meter connection tube. 2. Waste seed room vacuum tube. 3 . Waste seed storage room. 4. Waste seed room cover. 5. Bolt. 6. Switch device. 7. Vacuum fan. 8. Air pump. 9. Storage seed shell.

the air pump is blown into the storage seed shell through the hose, which makes the waste seeds in the storage seed shell stay loose, helping the waste seeds to be sucked into the waste seed recovery room by vacuum negative pressure along the hose. Under the double action of negative pressure generated by the vacuum fan and positive pressure produced by the air pump, the waste seed in the seed storage shell is quickly drawn inside along the hose, marking the completion of waste seeds' thorough recovery. When the waste seeds absorbed by vacuum negative pressure enter into the waste seed recovery room with sharply increased sectional area, the pressure will decline rapidly. The gravity of the seed is greater than the suction force of the vacuum negative pressure, causing the cotton seed to fall into the waste seed recovery room.

\section{Field Trials and Result Analysis of the Combined Air-Suction Seeder}

7.1. Test Materials and Methods. In September 2019, a field trial was carried out at the experimental station of agriculture on the south campus of Shandong Agricultural University (as shown in Figure 11).

During the trial, the seeder was driven by a Lovol 350 tractor with a power of $26 \mathrm{~kW}$. The soil is loam, whose moisture content amounts to $23.2 \%$. Before trial, the land is cultivated and leveled. The main instruments used in the test are combined air suction cotton seeder, ruler, stopwatch, moisture meter, and so on. The main technical parameters of

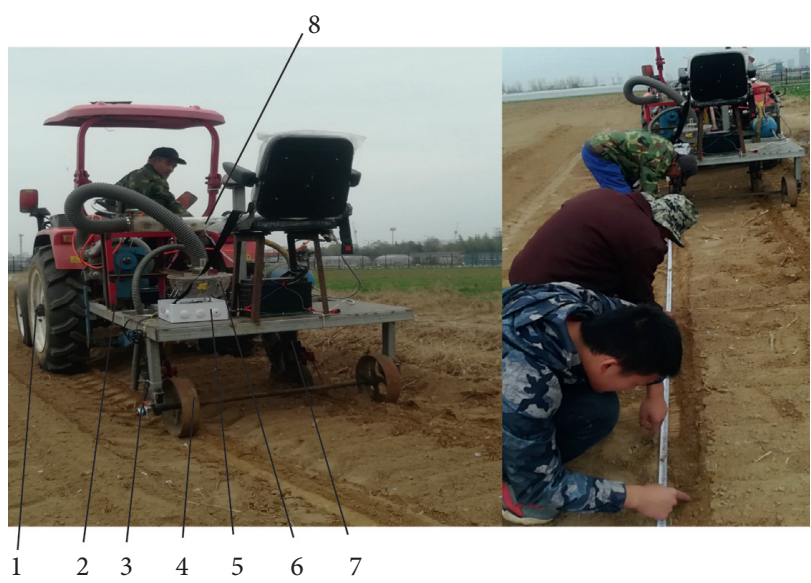

Figure 11: Field trial. (1) Tractor. (2) Vacuum fan. (3) Encoder. (4) Land wheel. (5) Control System. (6) Waste seed storage room. (7) Combined air suction seed meter. (8) Three-way switching device.

the combined air suction cotton plot planter (including tractor) are shown in the Table 1.

The performance test of seeding operation should be conducted in accordance with the test method specified in GB/T 6973-2005 "Operation Quality of Single Seed (Precision) Seeder," and the operation index shall be tested. The detection indexes mainly include the multiples rate, missing rate, coefficient of variation, and seed clearing rate.

7.2. Single Factor Test and Result Analysis. As for the cotton seed, it is concluded that the variation coefficient of its plant spacing during sowing has nothing to do with wind pressure and the width of air suction groove plate through analysis. If plant spacing remains the same, it is only related to the forward velocity of the seeder. In order to find a better forward velocity for the seeder to guide production, plant spacing is set at $20 \mathrm{~cm}$, with the forward velocity reaching $0.6,0.8,1.0,1.2,1.4,1.6,1.8,2$, and $2.2 \mathrm{~m} / \mathrm{s}$, respectively, which is $18,24,30,36,42,48,54,60$, and $66 \mathrm{r} / \mathrm{min}$, respectively, when being converted into rational speed of the seed metering device. Sowing $20 \mathrm{~m}$ with the same speed of each time, measuring the actual average plant spacing of 100 seeds that should be theoretically discharged within $20 \mathrm{~m}$, and calculating the coefficient of variation, the results of variation coefficient are shown in Figure 12.

As can be seen from Figure 12, the variation coefficient of plant spacing increases first, then decreases, and then increases up to be stable at a certain stage with the increase of the forward velocity of the seeder. That is because the combined air suction seeder relies on the rotation of guide groove plate to bring the cotton seeds to the metering funnel at the bottom of the seed metering device in the course of seeding.

In this way, different seeding states will appear when the cotton seed reaches the seeding funnel, and there will be different situations in the front, middle, and end of guide groove plate (Figure 13). When the speed is low, the cotton seeds move together with the front of guide groove plate. However, when approaching the seed outlet which is 
TABle 1: Technical parameters of combined air suction cotton seeder.

\begin{tabular}{lc}
\hline Parameter & Value \\
\hline Length $\times$ width $\times$ height $(\mathrm{m} \times \mathrm{m} \times \mathrm{m})$ & $3 \times 1.4 \times 1.2$ \\
Mating power $(\mathrm{kW})$ & 26 \\
Line spacing $(\mathrm{m})$ & $0.6-1.2$ \\
Plant spacing $(\mathrm{m})$ & $0.1-0.4$ \\
Sowing depth $(\mathrm{m})$ & $0-0.05$ \\
Line number & 2 \\
Seeder's forward velocity $(\mathrm{km} / \mathrm{h})$ & $0-15$ \\
\hline
\end{tabular}



Figure 12: Plant spacing variation coefficient results.

nearly level, the cotton seed will stop there and wait for the next row of guide groove plate which can push it to drop. The speed of guide groove plate is different, and the initial speed of the cotton seed when it falls is different, which will increase the coefficient of variation. As the speed increases, the movement speed of the cotton seed in guide groove plate expanses, and it does not stay in the seed outlet when approaching the seed outlet. At this time, the seeding is relatively even. As the speed continues to increase, the cotton seed will be constantly forced to move in guide groove plate, resulting in the same movement speed as the rotation speed of guide groove plate when reaching the seed metering funnel. So the cotton seeds have the lateral initial speed when falling, increasing the variation coefficient. After the field trial, data processing, and cause analysis, it can be concluded that the forward speed of the seeder with a small coefficient of variation is $1.2-1.5 \mathrm{~m} / \mathrm{s}$, which equals $36-45 \mathrm{r} / \mathrm{min}$ when converted into the seeder's rotation speed.

7.3. Orthogonal Test and Result Analysis. The main parameters influencing the multiples rate, missing rate, and plant spacing uniformity are forward velocity, vacuum negative pressure, and the width of air suction groove. In order to study the effect of parameters on seeding performance, an orthogonal experiment of 3 factors and 3 levels is designed based on the preliminary experiment conducted in the laboratory. The codes of experimental factors are shown in Table 2. Experiment design and response values are shown in Table 3.
Design-Expert is used for variance analysis of experimental data, and the significance test results of the regression equation are shown in Table 4. According to Table 4, the fitting degree of the multiples rate model $Y_{1}$ is extremely significant $(P<0.01)$. The lack of fit $P$ is 0.2596 , not significant, indicating that there are no other major factors affecting the indexes. $R^{2}$ is 0.86 , indicating that reliability is $86 \%$. According to the degree to which various factors could affect the multiples rates, they are ranked as follows: groove width $X_{2}$, vacuum negative pressure $X_{3}$, and speed $X_{1}$. The regression model after eliminating insignificant factors in the interaction terms is

$$
\begin{aligned}
Y_{1}(\%)=+33.6656 & -23.875 X_{1}-7.15 X_{2}-13.6875 X_{3} \\
& -4 X_{1} X_{2}+0.3125 X_{1} X_{3}-0.75 X_{2} X_{3} \\
+ & 18.4375 X_{1}^{2}+2.85 X_{2}^{2}+3.35937 X_{3}^{2} .
\end{aligned}
$$

Design-Expert is used to conduct variance analysis of experimental data, and the significance test results of the regression equation are shown in Table 5. According to Table 5, the fitting degree of the missing rate model $Y_{2}$ is extremely significant $(P<0.05)$. The lack of fit $P$ is 0.1308 , not significant, indicating that there are no other major factors affecting the indexes. $R^{2}$ is 0.9635 , indicating that reliability is $96.35 \%$. According to the degree to which various factors could affect the missing rates, they are ranked as follows: speed $X_{1}$, vacuum negative pressure $X_{2}$, and groove width $X_{3}$. The regression model after eliminating insignificant factors in the interaction terms is

$$
\begin{gathered}
Y_{2}(\%)=15.05+8.875 X_{1}+9.4 X_{2}-20.5 X_{3}+X_{1} X_{2} \\
+0.9375 X_{1} X_{3}+1.625 X_{2} X_{3}-6.875 X_{1}^{2}-3.1 X_{2}^{2}(9) \\
+2.8125 X_{3}^{2} .
\end{gathered}
$$

7.4. Optimal Parameter Optimization. In order to determine the optimal range of parameter value, the optimal parameter optimization sets the multiples index and missing index to be less than $3 \%$, whose total is less than $5 \%$. The optimal parameter range given by the Response Surface Methodology is as follows: speed ranges from 1.3 to $1.5 \mathrm{~m} / \mathrm{s}$, vacuum negative pressure ranges from 2.5 to $2.8 \mathrm{kPa}$, and groove width ranges from 2.6 to $2.8 \mathrm{~mm}$.

7.5. Seed-Clearing Performance Test and Result Analysis. In order to test the clearing performance (rapidity and thoroughness) of the combined air suction seeder, a trial seeder was used to conduct the seed clearing test in the field. It is concluded that the critical floating velocity of cotton seeds is about $13 \mathrm{~m} / \mathrm{s}$. When vacuum negative pressure (wind pressure) reaches about $2 \mathrm{kPa}$, the wind speed at the three-way switch device will reach about $24 \mathrm{~m} /$ $s$, greater than the critical speed of the cotton seed. Cotton seeds move 2 meters from waste seed storage (Figure 14) shell of the combined air suction seed metering device to waste seed storage room within about $0.1 \mathrm{~s}$. In the process 


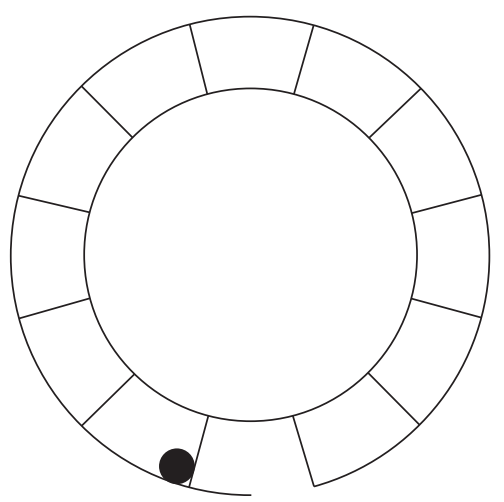

(a)

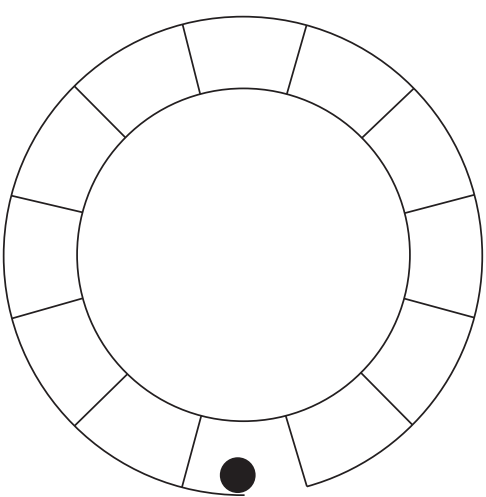

(b)

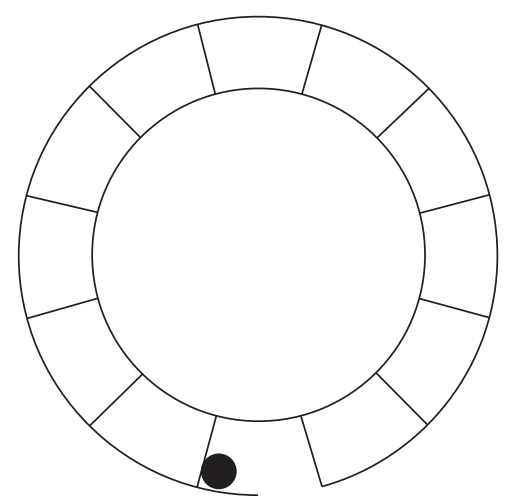

(c)

FIGURE 13: Seeds fall in different intervals. (a) Drop in the front. (b) Drop in the middle. (c) Drop in the end.

TABLE 2: Experimental factors of codes.

\begin{tabular}{lccc}
\hline Code & Speed $X_{1}(\mathrm{~m} / \mathrm{s})$ & Vacuum negative pressure $X_{2}(\mathrm{kPa})$ & The width of air suction groove $X_{3}(\mathrm{~mm})$ \\
\hline-1 & 1 & 2 & 2.4 \\
0 & 1.3 & 2.5 & 2.8 \\
1 & 1.6 & 3 & 3.2 \\
\hline
\end{tabular}

TABle 3: Experiment design and response values.

\begin{tabular}{lccccc}
\hline Serial number & Speed $(\mathrm{m} / \mathrm{s})$ & Groove width $(\mathrm{mm})$ & Vacuum negative pressure $(\mathrm{kPa})$ & Multiples index $(\%)$ & Missing index $(\%)$ \\
\hline 1 & 0.6 & 2 & 2.6 & 2.2 & 1.2 \\
2 & 1.6 & 2 & 2.6 & 4.9 & 1.3 \\
3 & 0.6 & 3 & 2.6 & 2.3 & 2.6 \\
4 & 1.6 & 3 & 2.6 & 1.5 & 0 \\
5 & 0.6 & 2.5 & 2.2 & 3.4 & 1.9 \\
6 & 1.6 & 2.5 & 2.2 & 2.4 & 0 \\
7 & 0.6 & 2.5 & 3 & 2.3 & 1.2 \\
8 & 1.6 & 2 & 2.2 & 2.9 & 3.2 \\
9 & 1.3 & 3 & 2.2 & 3 & 1.5 \\
10 & 1.3 & 2 & 3 & 4.6 & 1.4 \\
11 & 1.3 & 3 & 3 & & \\
\hline
\end{tabular}

TABLE 4: Variance analysis of multiples index.

\begin{tabular}{|c|c|c|c|c|c|c|}
\hline Source of variance & Quadratic sum & Degree of freedom & Mean square error & $F$ & $P$ & \\
\hline Model & 24.64 & 9 & 2.74 & 10.54 & 0.0026 & $* *$ \\
\hline$X_{1}$ & 4.06 & 1 & 4.06 & 15.64 & 0.0055 & $* *$ \\
\hline$X_{2}$ & 7.61 & 1 & 7.61 & 29.29 & 0.001 & $* *$ \\
\hline$X_{3}$ & 5.95 & 1 & 5.95 & 22.92 & 0.002 & $* *$ \\
\hline$X_{1} X_{2}$ & 0.64 & 1 & 0.64 & 2.46 & 0.1604 & \\
\hline$X_{1} X_{3}$ & 0.0025 & 1 & 0.0025 & 0.0096 & 0.9246 & \\
\hline$X_{2} X_{3}$ & 0.09 & 1 & 0.09 & 0.3466 & 0.5745 & \\
\hline$X_{1}^{2}$ & 2.29 & 1 & 2.29 & 8.82 & 0.0208 & $*$ \\
\hline$X_{2}^{2}$ & 2.14 & 1 & 2.14 & 8.23 & 0.024 & $*$ \\
\hline$X_{3}^{2}$ & 1.22 & 1 & 1.22 & 4.69 & 0.0672 & \\
\hline Residual error & 1.82 & 7 & 0.2596 & & & \\
\hline Lack of fit & 1.82 & 3 & 0.6058 & & & \\
\hline Error & 0 & 4 & 0 & & & \\
\hline Total & 26.46 & 16 & & & & \\
\hline
\end{tabular}

${ }^{*}$ Significant difference $(P<0.05) .{ }^{* *}$ Extremely significant difference $(P<0.01)$. 
TABLE 5: Variance analysis of missing index.

\begin{tabular}{|c|c|c|c|c|c|c|}
\hline Source of variance & Quadratic sum & Degree of freedom & Mean square error & $F$ & $P$ & \\
\hline Model & 10.37 & 9 & 1.15 & 20.55 & 0.0003 & $* *$ \\
\hline$X_{1}$ & 2.53 & 1 & 2.53 & 45.14 & 0.0003 & $* *$ \\
\hline$X_{2}$ & 2.31 & 1 & 2.31 & 41.22 & 0.0004 & $* *$ \\
\hline$X_{3}$ & 1.45 & 1 & 1.45 & 25.77 & 0.0014 & $* *$ \\
\hline$X_{1} X_{2}$ & 0.0400 & 1 & 0.0400 & 0.7134 & 0.4262 & \\
\hline$X_{1} X_{3}$ & 0.0225 & 1 & 0.0225 & 0.4013 & 0.5466 & \\
\hline$X_{2} X_{3}$ & 0.4225 & 1 & 0.4225 & 7.54 & 0.0287 & $*$ \\
\hline$X_{1}^{2}$ & 0.3184 & 1 & 0.3184 & 5.68 & 0.0487 & $*$ \\
\hline$X_{2}^{\frac{1}{2}}$ & 2.53 & 1 & 2.53 & 45.10 & 0.0003 & $* *$ \\
\hline$X_{3}^{2}$ & 0.8526 & 1 & 0.8526 & 15.21 & 0.0059 & $* *$ \\
\hline Residual error & 0.3925 & 7 & 0.0561 & & & \\
\hline Lack of fit & 0.3925 & 3 & 0.1308 & & & \\
\hline Error & 0.0000 & 4 & 0.0000 & & & \\
\hline Total & 10.76 & 16 & & & & \\
\hline
\end{tabular}

${ }^{*}$ Significant difference $(P<0.05) .{ }^{* *}$ Extremely significant difference $(P<0.01)$.

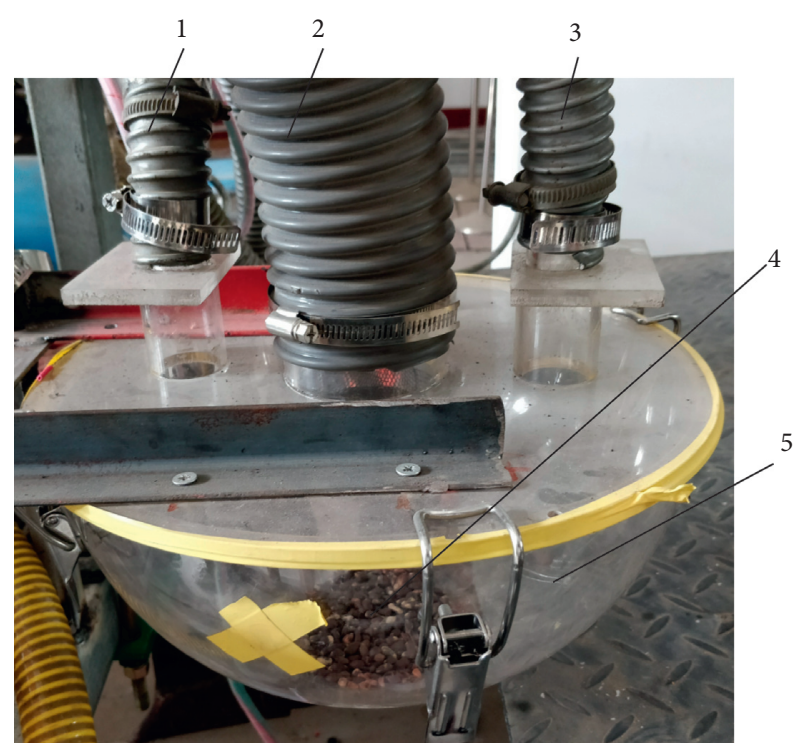

Figure 14: Waste seed storage room. (1 and 3) Interface for seed storage shell. (2) interface for vacuum fan. (4) Waste seed. (5) Waste seed storage room.

of programming the control system of the combined air suction seeder, the electromagnetic valve switching time of the three-way switch device is set to $5 \mathrm{~s}$ at the beginning. When the system is switched to seed clearing, the vacuum negative pressure (wind pressure) generated by the vacuum fan and the positive pressure provided by the air pump are used for seed blowing. It further makes seeds more likely be cleaned. In the field trial of seed clearing, the detection index is only the seeds' residual rate in the seed storage shell.

The field trial is carried out to test different vacuum negative pressure including 2.2, 2.6, and $3 \mathrm{kPa}$. Each group of vacuum negative pressure carries out 20 seed clearing operations during which 20 cotton seeds are added to the seed storage shell. Results show that the residual rate is 0 in every operation, which means that the seed clearing rate is $100 \%$, achieving thorough seed clearing.

\section{Conclusion}

A combined air suction seed metering device is designed, which can realize precise seed metering, clean and rapid seed clearing, and can further improve the accuracy and rapidity of cotton tablet seeding. The seed metering system and seed clearing system are also designed and analyzed at the same time.

Velocity's influence on seed metering uniformity is analyzed through single-factor test. It is found that the variation coefficient of seed metering increases first, then decreases, and then increases up to be stable with the increase of planting speed. It is determined that the better forward speed of the seeder is $1.2-1.5 \mathrm{~m} / \mathrm{s}$.

The combined air suction cotton seeder is employed in the field trial. Design-Expert is used for designation and analysis. According to the degree to which various factors could affect the multiples rates, they are ranked as follows: groove width, vacuum negative pressure, and speed. According to the degree to which various factors could affect the missing rates, they are ranked as follows: speed, vacuum negative pressure, and groove width. The optimal parameter range is speed $1.3-1.5 \mathrm{~m} /$ $\mathrm{s}$, vacuum negative pressure $2.5-2.8 \mathrm{kPa}$, and groove width $2.6-2.8 \mathrm{~mm}$. The field trial examined the seed-clearing system's performance, and the seed clearing rate has reached $100 \%$, meeting the seeding requirements in a cotton tablet.

\section{Data Availability}

The data used to support the findings of this study are currently under embargo while the research findings are commercialized. Requests for data, 12 months after publication of this article, will be considered by the corresponding author.

\section{Conflicts of Interest}

The authors declare that they have no conflicts of interest.

\section{References}

[1] Y. Shuxun, "Mechanized cotton planting can save $70 \%$ of cotton planting labor costs in the future," Rural Knowledge, vol. 2, p. 13, 2015. 
[2] C. Shen, Exploration of Interspecific Variation, Application of QTL Mapping and Genome-wide Interpretation of Recombination Variation in cotton, Huazhong Agricultural University, Wuhan, China, 2019.

[3] A. Yazgi, A. Degirmencioglu, I. Onal, and E. Bayram, "Optimization of the seed spacing uniformity performance of a precision seeder using spherical materials and response methodology," in Proceedings of the ASABE Annual International Meeting, Pittsburgh Pennsylvania, March 2010.

[4] M. Kara, A. K. Bayhan, I. Ozsert, and Y. Yildirim, "Performance of fluted roll metering devices in seed drills with ammonium sulphate and diammonium phoshate," Applied Engineering in Agriculture, vol. 26, no. 2, pp. 197-201, 2010.

[5] T. Furumoto, M. R. Alkahari, T. Ueda, M. S. Abdul Aziz, and A. Hosokawa, "Monitoring of laser consolidation process of metal powder with high speed video camera," Physics Procedia, vol. 39, pp. 760-766, 2012.

[6] R. J. Orth, S. R. Marion, S. Granger, and M. Traber, "Evaluation of a mechanical seed planter for transplanting Zostera marina (eelgrass) seeds," Aquatic Botany, vol. 90, no. 2, pp. 204-208, 2009.

[7] L. Yeyu, S. Lulu, L. Dongsheng et al., "Research on function innovation of wheat plot seeder in Lixia River compaired a new Lixiahe plot seeder for wheat breeding," Journal of Anhui Agricultural Sciences.vol. 45, no. 29, pp. 194-196, 207.

[8] L. Shuguang, Study on Design and Mechanism Analysis of Main Parts of Plot Seeder, Shenyang Agricultural University, Shenyang, China, 2012.

[9] L. Zhaodong, "Study on seeding technology and working mechanism of pneumatic-typed precision centralized metering device for rapeseed," Huazhong Agricultural University, Wuhan, China, 2016.

[10] L. Qingxi, Y. Song, L. Yitao, C. Mianling, and W. Lei, "Modeling for performance and parameters of pneumatic seed-metering system of precision planter for rapeseed," Journal of Agricultural Engineering, vol. 29, no. 17, pp. 9-15, 2013.

[11] Y. Binghui, W. Wei, L. Tianyi, M. Xueting, and Y. Shujun, "Design of cotton plot precise seeder in Xinjiang," Journal of Agricultural Mechanization Research, vol. 41, no. 05, pp. 6570, 2019.

[12] S. Yu, "The development of cotton production in the recent hundred years of China," Journal of Agricultural, vol. 8, no. 1, pp. 85-91, 2018.

[13] M. Jiang, C. Liu, W. Dan, X. Du, P. Cai, and J. Song, "Design and test of wide seedling strip wheat precision planter," Transactions of the Chinese Society for Agricultural Machinery, vol. 50, no. 11, pp. 53-62, 2019.

[14] F. Bertrand, L.-A. Leclaire, and G. Levecque, "DEM-based models for the mixing of granualr materials," Chemical Engineering Science, vol. 60, no. 8-9, pp. 2517-2531, 2005.

[15] Z. Cunpeng, Z. Guiyuan, G. Baosheng, and G. Junyi, "Current situation and existing problems of cotton mechanical sowing method," Hebei Farm Machinery, vol. 4, p. 18, 2017.

[16] W. Lei, C. Yongcheng, and W. Weixin, "Status quo and developing direction of cottonseed metering device," Chinese Agricultural Mechanization, vol. 3, pp. 80-82, 2005.

[17] W. Fenghua, S. Kai, L. Qinghui, D. Jiayu, S. Wei, and Y. Qingxu, "Design and experiment of minituber precision single-row air-suction planter," Transactions of the Chinese Society for Agricultural Machinery, vol. 51, no. 1, pp. 66-76, 2020.

[18] L. Wenzheng, H. Jin, L. Hongwen, L. Xueqiang, W. Zhongcai, and L. Peng, "Design and experiment of vibration-arranging based seeder for potato micro-seed," Transactions of the Chinese Society for Agricultural Machinery, vol. 50, no. 8, pp. 70-80, 2019.

[19] L. Weiwen, G. Fengwei, W. Feng, X. Hongbo, C. Youqing, and H. Zhichao, "Design and experiment of wheat planter with straw crushing and Inter-furrow collecting-mulching under full amount of straw and root stubble cropland," Transactions of the Chinese Society for Agricultural Machinery, vol. 50, no. 12, pp. 42-52, 2019.

[20] L. Fei, Z. Manquan, and W. Yingsi, "Design of scooping plastic film mulch planter and seeding performance test of cotton," Journal of Agricultural Mechanization Research, vol. 7, pp. 135-138, 2015.

[21] Y. Chunfeng, Y. Zidong, Y. Bingxin, and D. Ruicheng, "Design of a cotton planter for film covering based on the rotation system of wheat and cotton," Journal of Agricultural Mechanization Research, vol. 66, no. 8, pp. 59-61, 2014.

[22] W. Jikui, G. Kangquan, L. Xinmin, J. Bei, and L. Bin, "Highspeed photography analysis on seed movement in seed chamber of clamping dibber wheel," Journal of Jiangsu University (Natural Science Edition), vol. 33, no. 1, pp. 11-15, 2012.

[23] X. He, Z. Ying, C. Xiaoman et al., "Experiment and analysis of dropping trajectory on rice pneumatic metering device," Transactions of the Chinese Society of Agricultural Engineering, vol. 12, pp. 23-30, 2015.

[24] S. Song, Z. Dongxing, Y. Li, C. Tao, L. Kehong, and Y. Xiaowei, "Simulation and verification of seed-filling performance of pneumatic-combined holes maize precision seedmetering device based on EDEM," Transactions of the Chinese Society of Agricultural Engineering, vol. 3, pp. 62-69, 2015. 